\title{
COMMENTARY
}

\section{Documenting the prevalence of cryptorchidism and hypospadias}

\section{Diego Barrieras, MD, FRCSC}

Chief, Urology Division, CHU Sainte-Justine, Urology Program Director, University of Montreal, Montreal, QC

See related article on page 167.

Cite as: Can Urol Assoc J 2011;5(3):172; D01:10.5489/cuaj.11074

was impressed by the efforts the authors made to document the prevalence of cryptorchidism and hypospadias over such a long period of time. ${ }^{1}$ Although there are small fluctuations during the period studied, there seems to be a diminution of cryptorchidism in recent years. This change occurs in spite of the fact that the age of surgery has now shifted from over the age of 5 to under the age of 2 (or less than a year). Due to referral patterns and surgical practice, cryptochidism was certainly underreported in the registry in its early years. The real difference is most probably higher.

It is also interesting to note that regional differences exist, and that some regions have a combined hypospadias and cryptorchidism prevalence that are higher than others. This may in fact be associated with environmental exposures as the authors have hypothesized, but may also be related to genetic determinants. Further studies may help define these differences, especially for the province of Quebec, where there seems to be a higher prevalence than reported in the literature.

Competing interests: None declared.

This paper has been peer-reviewed.

\section{Reference}

1. Guertin S, Lemieux S, Makhoulian N, et al. Variation spatiotemporelle de la cryptorchidie et de l'hypospadias au Québec : Une étude exploratoire. Can Urol Assoc J 2011;5: 167-71; D01:10.5489/cuaj.10090.

Correspondence: Dr. Diego Barrieras, CHU Sainte-Justine, Centre de recherche, 3175 Chemin de la Côte Sainte Catherine, Montreal, QC H3T 1C5; fax: 514-345-4825; diego_barrieras@ssss. gouv.qc.ca 